\title{
Prognostic Factors and Survival of Laryngeal Cancer in Cameroon
}

\section{Jean Paul Engbang1,2, Maurice Mpessa², Laurence Essama ${ }^{1,3}$, Samad Abdel Mohamadou1, Louis Richard Njock ${ }^{1}$}

\author{
${ }^{1}$ Faculty of Medicine and Pharmaceuticals Sciences, The University of Douala, Douala, Cameroon \\ ${ }^{2}$ Douala Laquintinie Hospital, Douala, Cameroon \\ ${ }^{3}$ Douala General Hospital, Douala, Cameroon \\ Email: jean_pen@yahoo.ca,jpauleng@gmail.com, mekobo@yahoo.fr, laubell@yahoo.fr, mohamadou.abdel@yahoo.fr, \\ rnjock@yahoo.fr
}

How to cite this paper: Engbang, J.P., Mpessa, M., Essama, L., Mohamadou, S.A. and Njock, L.R. (2021) Prognostic Factors and Survival of Laryngeal Cancer in Cameroon. International Journal of Otolaryngology and Head \& Neck Surgery, 10, 30-42. https://doi.org/10.4236/ijohns.2021.101004

Received: November 30, 2020

Accepted: January 24, 2021

Published: January 27, 2021

Copyright $\odot 2021$ by author(s) and Scientific Research Publishing Inc. This work is licensed under the Creative Commons Attribution International License (CC BY 4.0).

http://creativecommons.org/licenses/by/4.0/

\begin{abstract}
Background: Laryngeal cancer is a major cause of morbidity and mortality worldwide. It is ranked worldwide as the second ENT cancer with 238,000 new cases and 106,000 deaths each year. In Africa, data on the prognostic factors and the survival of this pathology remain quite limited. Objective: To study the prognostic factors of laryngeal cancer and the survival of patients with laryngeal cancer in Yaoundé and Douala. Methods and Materials: We performed an analytical, longitudinal (retrospective) study over a period from January 1, 2009 to December 31, 2018 including all patients with histologically proven laryngeal cancer, at the ENT, oncological, anatomopathological, radiotherapy and surgery Department of three reference health structures in the cities of Douala and Yaoundé (Laquintinie Hospital and General Hospital of Douala, General Hospital of Yaounde). The data collected were recorded and analyzed by SPSS version 25 and Excel 2013 statistical computer software. Survival was determined by the Kaplan Meier method and the search for prognostic factors was carried out using the Cox proportional hazards model. The significance level was $\mathrm{p}=0.05$. Results: We selected 80 patients whose vital status we knew and who had been followed up after histological evidence. The sex ratio was 5.66. The median age at cancer diagnosis was 62 years old. 60 (75\%) were exposed to tobacco, $52(65 \%)$ had alcohol-tobacco poisoning. The Center and Littoral regions were the most represented with $37.5 \%$ and $48.8 \%$ respectively. Dysphonia was present in $98.8 \%$ of patients. The histological type encountered was squamous cell carcinoma in 78 patients; in the majority of cases the cancer was diagnosed at stage IV and the glottis was the most frequent site $(86.2 \%)$. The median overall survival was 1.41 with $95 \%$ CI [1.08 - 1.74]. The overall survival rates at 1 year, 3 years, 5
\end{abstract}


years and 8 years were $70 \%, 18 \%, 3 \%$ and $1.5 \%$, respectively. The poor prognosis factor found was: age greater than or equal to 70 years. Conclusion: Present study showed that survival in laryngeal cancer in Cameroon is very low with a median overall survival of 1.41 years. The overall survival rates at 1 year, 3 years, 5 years and 8 years are $70 \%, 18 \%, 3 \%$ and 1.5\%, respectively. The age greater than or equal to 70 years is the poor prognosis factor, while receiving surgery in combination with neoadjuvant chemotherapy or surgery in combination with adjuvant radiotherapy is the factor of good prognosis.

\section{Keywords}

Laryngeal Cancer, Prognostic Factors, Survival, Cameroon

\section{Introduction}

Laryngeal cancer is one of the cancers of the upper aero-digestive tract and accounts for $3 \%$ of cancers in humans worldwide [1] [2]. In the majority of cases, it affects men with a sex ratio of 8 men to 2 women [2]. It mainly occurs between 45 and 70 years [2]. Worldwide, there are 238,000 new cases each year and 106,000 deaths annually [3]. In North America and the United States in particular, there are approximately 13,000 cases and 3660 deaths each year due to laryngeal cancer [3]. In Europe, the incidence of laryngeal cancer in men in 2012 was 35,981 cases with a mortality of 18,069 of these cases [4]. In French-speaking Africa, its incidence is 0.6 per 100 inhabitants [4]. For a patient with cancer of the larynx, clinical examination, imaging and endoscopy under general anesthesia, and histology are essential to establish the diagnosis, study the tumor and its extensions, look for metastatic lymphadenopathy and synchronous localization [1]. The most frequent histopathological form is squamous cell carcinoma and accounts for $95 \%$ of laryngeal cancers [5]. Its treatment depends on the evolutionary stage of the tumor and poses the challenge of laryngeal preservation. This treatment oscillates between very aggressive amputation surgery and still promising chemoradiotherapy, without omitting the role of prevention as a definite therapeutic component [6]. Several factors are associated with the occurrence of these cancers, but tobacco is so far the most incriminated factor with a presence in $98 \%$ of patients [7]. The prognosis of laryngeal cancer is linked to several factors. Thus the site of the cancer, the age and sex of the patient, the TNM stage, the association of laryngeal cancer with other non-neoplastic pathologies and anemia have been identified in North America, Europe and Asia, and in some African countries [6] [8] [9]. The overall survival rate of patients worldwide is between $66 \%-89.7 \%$ all stages combined [6]. In North America, a Canadian study shows that it is $62 \%$ at 5 years [10]. In Europe, the net survival in France is $61.6 \%$ at 5 years [11]. In Africa, a study done in Morocco on glottal cancer reports a survival rate of 77\% [12]. In Cameroon, a few studies have been carried out on laryngeal cancer, namely a study carried out by Mvouni et al. in 
2006 which found a 3-year survival rate close to $21 \%$ [13]. It emerges from the above that few studies have been devoted to laryngeal cancer, hence our interest in studying this pathology and in particular on prognostic factors and patient survival.

\section{Patients and Methods}

This was a retrospective cohort study conducted among laryngeal cancers patients at the ENT, oncological, anatomopathological, radiotherapy and surgeryDepartment of three reference health structures in the cities of Douala and Yaoundé (Laquintinie Hospital and General Hospital of Douala, General Hospital of Yaounde), were retrospectively retrieved from the medical records of those department databases with a 100\% rate of accuracy, from January 1, 2009 to December 31, 2018. We carried out non-probability sampling. Records showing complete clinical examination, indicating the presence of malignant tumour in the larynx were included. Patients with other laryngeal conditions and histopathological confirmed non-malignanttumours were excluded. The information was collected on a data collection sheet that we designed, pre-tested and readjusted according to the dysfunctions observed. A trained medical staff took part in this collection. The different sociodemographic, clinical, paraclinical, therapeutical and evolutive data were filled in the questionnaires and the patients or their relatives contacted through phone calls in order to know their vital states and complete all possible lacking information. This information was registered and processed using SPPS version 20 software and Microsoft Excel 2016. We carried out a descriptive analysis of the studied population, the different associations between clinicopathological variables and tumour location was performed using the $\chi 2$ test. or Fisher's exact test. Univariate analysis was performed by performing the survival curves according to the Kaplan-Meier method and the difference in survival was compared statistically by the Log Rank test. Variables statistically significant in univariate analysis were secondarily introduced into the Cox regression model for multivariate analysis. Statistical significance was set at a value of $\mathrm{p}<0.05$.

This work had received an ethical clearance from the Ethics Committee of the University of Douala, who granted us ethical clearance No 2108 CEI-UDo/07/ 2020/T, to conduct our study in strict compliance with the ethics.

\section{Results}

We collected data in 111 files of patients with laryngeal cancer whose diagnosis was made between January 1, 2009 and December 31, 2018. Among the 111 files recruited, 31 files were excluded according to the inclusion criteria. Thus, 80 patients were found for our study.

\subsection{Survival}

We studied the overall survival of our study population, according to socio-de- 
mographic variables, lifestyle, clinical, paraclinical and therapeutic characteristics, as presented in Table 1 and Table 2.

The median overall survival in our study was 1.41 years with a confidence interval (95\% CI) of (1.08 - 1.74). The overall survival at one year, three years, five years and eight years are at $70 \%, 18 \%, 3 \%$ and $1.5 \%$ respectively (Figure 1 ).

As shown in Figure 2, the median progression-free survival is 3.08 years with a confidence interval (95\% CI) of (1.17 - 4.14). One-year, three-year, five-year, and eight-year progression-free survival is $83 \%, 53.5 \%, 38 \%$ and $38 \%$ respectively.

Survival with progression shows to us through this curve that one-year, three-year, five-year, and eight-year progression survival were $85 \%, 30 \%, 4.8 \%$, and $2.5 \%$, respectively. The median survival with progression was 2.66 years with a confidence interval $(95 \% \mathrm{CI})$ of (2.11 - 3.21) (Figure 3).

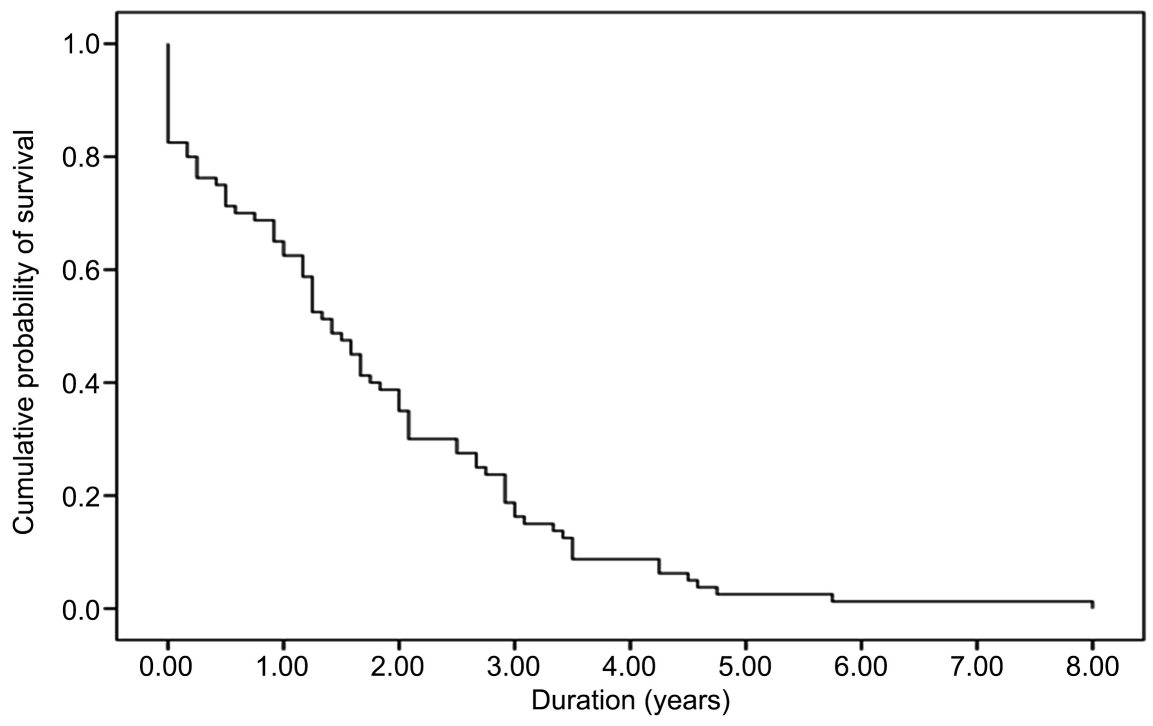

Figure 1. Représentation de la survie globale.

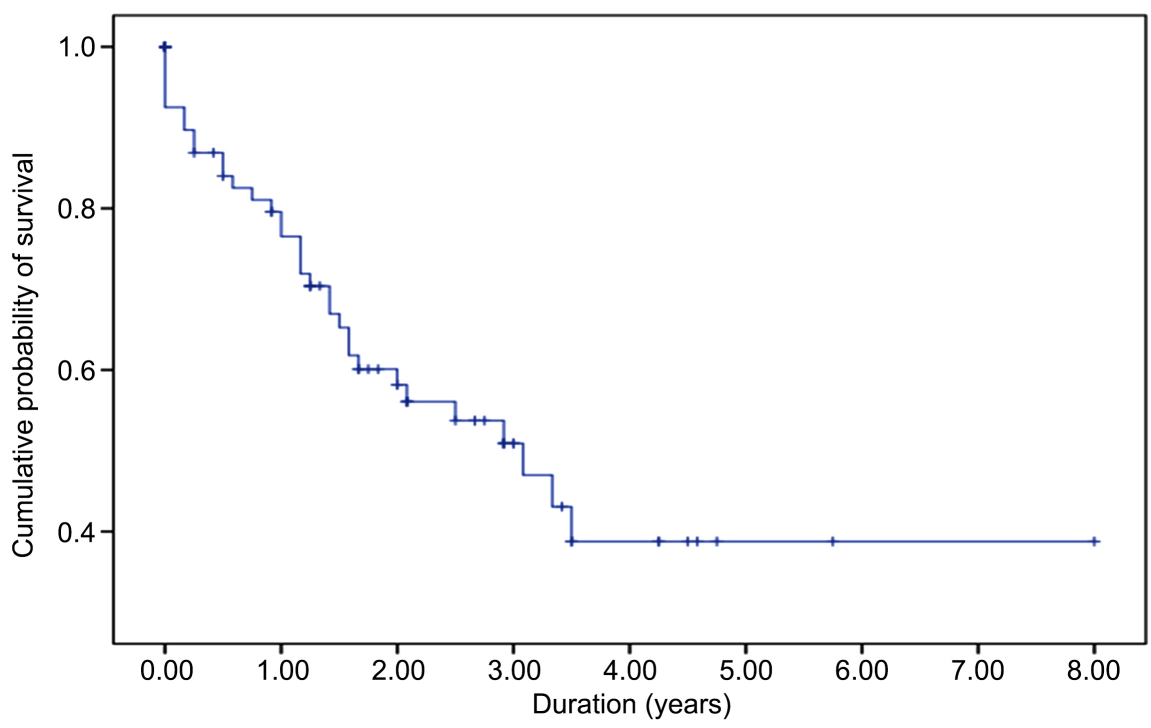

Figure 2. Progression-free survival curve. 


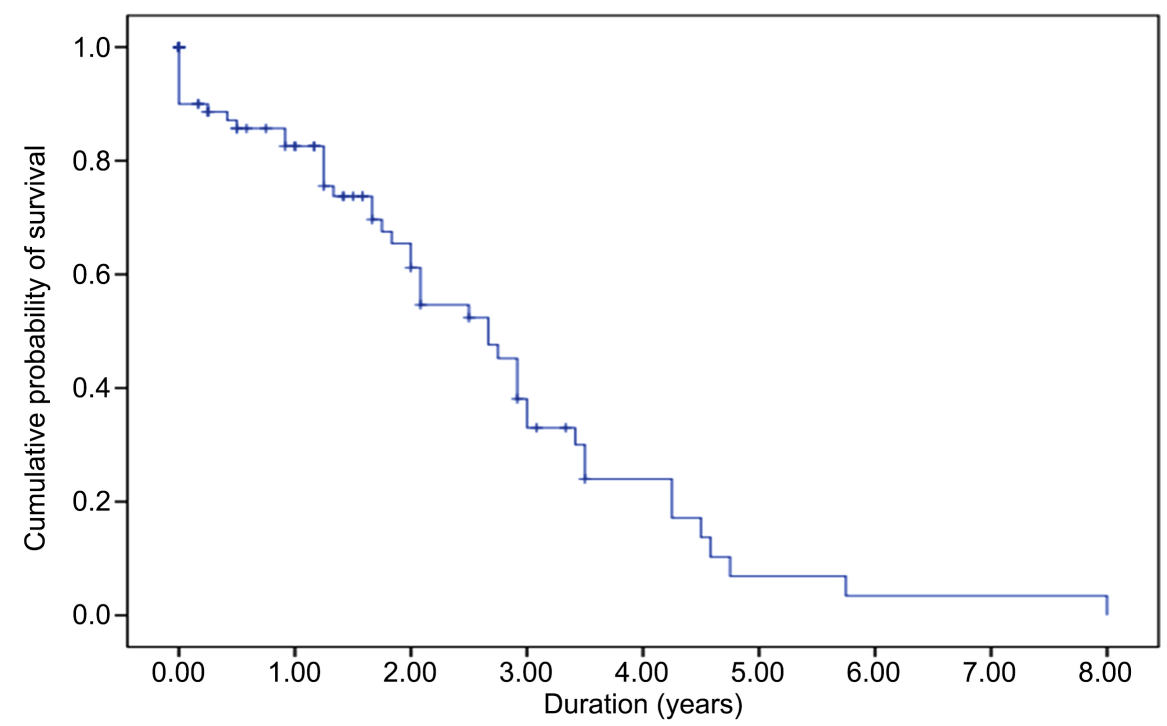

Figure 3. Survival curve with progression.

Table 1. Association of socio-demographic and lifestyle characteristics with survival using log rank test.

\begin{tabular}{|c|c|c|c|}
\hline Variable & Frequency (n. \%) & Median OS (95\% CI) (months) & p-value \\
\hline \multicolumn{4}{|l|}{ Age (Years) } \\
\hline$<40$ & $2(2.5 \%)$ & $4(2.79-5.5)$ & $0.001^{\star}$ \\
\hline $40-49$ & $11(13.8 \%)$ & $2.91(2.48-3.35)$ & \\
\hline $50-59$ & $14(17.5 \%)$ & $2.91(2.61-3.22)$ & \\
\hline $60-69$ & $37(46.3 \%)$ & $1.41(1.16-1.66)$ & \\
\hline $70+$ & $16(20.0 \%)$ & $0.25(0.03-0.46)$ & \\
\hline \multicolumn{4}{|l|}{ Sex } \\
\hline Women & $12(15.0 \%)$ & $1.66(0.44-2.89)$ & 0.932 \\
\hline Men & $68(85.0 \%)$ & $1.25(0.87-1.62)$ & \\
\hline \multicolumn{4}{|l|}{ Smoking } \\
\hline No & $20(25.0 \%)$ & $1.42(0.68-2.14)$ & 0.484 \\
\hline Yes & $60(75.0 \%)$ & $1.25(0.69-1.80)$ & \\
\hline \multicolumn{4}{|l|}{ Alcoholism } \\
\hline No & $17(21.2 .0 \%)$ & $1.04(1.2-5.01)$ & 0.105 \\
\hline Yes & $63(78.8 \%)$ & $2.02(0.87-10.4)$ & \\
\hline \multicolumn{4}{|l|}{ BMI } \\
\hline Underweight & $26(32.5 \%)$ & $2.83(1.01-7.9)$ & 0.218 \\
\hline Normal weight & $40(50.0 \%)$ & $4.33(1.53-11.6)$ & \\
\hline overweight & $14(17.5 \%)$ & $0.12(0.01-1.01)$ & \\
\hline
\end{tabular}


Table 2. Association of clinical, pathological and therapeutic parameters with survival using log rank test.

\begin{tabular}{|c|c|c|c|}
\hline Variable & $\begin{array}{l}\text { Frequency } \\
\quad(n, \%)\end{array}$ & $\begin{array}{c}\text { Median OS }(95 \% \mathrm{CI}) \\
\text { (months) }\end{array}$ & $\mathrm{p}$-value \\
\hline \multicolumn{4}{|c|}{ Consultation delay (Months) } \\
\hline$<3$ & $6(7.5 \%)$ & $3(0.29-5.70)$ & $0.005^{*}$ \\
\hline$[3-6]$ & $5(6.3 \%)$ & $2.91(2.39-3.13)$ & \\
\hline$[6-12]$ & $3(3.8 \%)$ & $2.91(0-7.58)$ & \\
\hline$>12$ & $66(82.5 \%)$ & $1.25(0.94-1.55)$ & \\
\hline \multicolumn{4}{|c|}{ Diagnosis time (Months) } \\
\hline$<1$ & $18(22.5 \%)$ & $0.5(0.03-7.99)$ & 0.101 \\
\hline$[1-2]$ & $39(48.75 \%)$ & $1.0(0.05-18.92)$ & \\
\hline$[2-4]$ & $22(27.5 \%)$ & $1.67(0.29-9.76)$ & \\
\hline$>4$ & $1(1.25 \%)$ & - & \\
\hline \multicolumn{4}{|c|}{ Depth of Tumour Invasion } \\
\hline $\mathrm{T} 1$ & $3(7.1 \%)$ & $0.25(0.11-0.38)$ & 0.096 \\
\hline $\mathrm{T} 2$ & $22(27.8 \%)$ & $1.16(0.85-1.47)$ & \\
\hline $\mathrm{T} 3$ & $29(36.7 \%)$ & $1.66(0-4.57)$ & \\
\hline $\mathrm{T} 4$ & $25(32 \%)$ & $1.58(0.73-4.3)$ & \\
\hline \multicolumn{4}{|c|}{ Lymph node involvement } \\
\hline N1 & $11(25 \%)$ & $0.5(0-1.10)$ & 0.125 \\
\hline $\mathrm{N} 2$ & $28(63.6 \%)$ & $1.16(0.73-1.59)$ & \\
\hline N3 & $3(6.81 \%)$ & $4.25(0-9.85)$ & \\
\hline \multicolumn{4}{|l|}{ Distant Metastasis } \\
\hline M0 & $44(55.8 \%)$ & $1.58(0.68-2.48)$ & $0.002^{*}$ \\
\hline M1 & $30(38.2 \%)$ & $1.16(0.73-1.53)$ & \\
\hline \multicolumn{4}{|l|}{ Metastasis location } \\
\hline Absence & $30(37.4 \%)$ & $1.58(0.68-2.48)$ & $0.002^{*}$ \\
\hline Lung & $18(22.5 \%)$ & $0.25(0-1.13)$ & \\
\hline Lung. vertebra & $5(6.2 \%)$ & - & \\
\hline Spine (cervical) & $1(1.2 \%)$ & $2.08-\mathrm{NC}$ & \\
\hline \multicolumn{4}{|l|}{ TNM tumour stage } \\
\hline Stage 1 & $8(10.0 \%)$ & $2.66(2.08-3.24)$ & $0.001^{*}$ \\
\hline Stage 2 & $27(33.8 \%)$ & $1.66(1.10-2.23)$ & \\
\hline Stage 3 & $26(32.5 \%)$ & $1.33(1.12-1.54)$ & \\
\hline Stage 4 & $19(23.8 \%)$ & $0.58(0-1.53)$ & \\
\hline
\end{tabular}


Continued

\begin{tabular}{cccc}
\hline Histological type & & & \\
Squamous cell carcinoma & $78(97.5 \%)$ & $1.41(1.05-1.77)$ & 0.742 \\
Verrucous carcinoma & $1(1.2 \%)$ & - & \\
Adenocarcinoma & $1(1.2 \%)$ & - & $0.007^{*}$ \\
Surgical resection margin & & & \\
Healthy & $45(68.1 \%)$ & $2.08(1.07-3.08)$ & \\
Invaded & $21(31.9 \%)$ & $1.25(0.62-1.87)$ & \\
Treatment & & & \\
Shimiotherapy + radiotherapy & $13(16.3 \%)$ & $1(0.37-1.62)$ & \\
Surgery + chemotherapy & $6(7.5)$ & $0.19(0.01-3.95)$ & \\
Surgery + Radiotherapy & $34(42.5 \%)$ & $1.3(0.61-2.04)$ & \\
Surgery + Chemotherapy + Radiotherapy & $21(26.3 \%)$ & $1.75(1.36-2.13)$ & \\
Exclusive surgery & $6(7.5 \%)$ & $0.41(0.15-0.68)$. & \\
\hline
\end{tabular}

\subsection{Pronostic Factors}

\subsubsection{Log Rank Test}

Table 1 shows that the only socio-demographic and lifestyle characteristic which was statistically significant association with survival was age $(\mathrm{p}=0.001)$; Patients who 60 - 69 years old or more than 70 years, had low median survival time (60 69 years $=1.41$ months, $70+=0.25$ months) compared to more young people. There was no significant association between survival and other variables.

As shown in Table 2, treatment modality was significantly associated with survival $(p=0.008)$. Surgical resection margin was also associated with survival $(\mathrm{p}=0.007)$. The median survival time of patient who healthy surgical resection margin was higher (2.08 months) compared to those with invaded (1.25 months). TNM stage was also significantly associated with survival $(\mathrm{p}=0.001)$ with patient in stage 4 having the least median survival time (0.58 months). There was significant difference concerning delay $(\mathrm{p}=0.005)$; patients who consulted very late (after 12 months) had low median survival (1.25 months) compared to early consultation (3 months). The presence of distance metastasis was also significantly associated with survival $(\mathrm{p}=0.002)$. Other parameters were not significantly associated with survival.

\subsubsection{Multivariate Analysis (Cox regression)}

According to the cox regression analysis, age $\geq 70$ years $(\mathrm{HR}=19.52, \mathrm{p}=0.027)$, surgical treatment combined with neoadjuvant chemotherapy $(\mathrm{HR}=0.42, \mathrm{p}=$ $0.039)$ and surgical treatment combined with radiotherapy $(\mathrm{HR}=0.45, \mathrm{p}=$ 0.019 ) were variable that were significantly associated with survival. But, it is important to notice that, age $\geq 70$ was a factor of poor prognosis; while age $<40$ were the factors of good prognosis (Table 3 ). 
Table 3. Association of different characteristics with survival using Cox regression analysis.

\begin{tabular}{|c|c|c|}
\hline Variable & HR (IC 95\%) & $\mathrm{p}$-value \\
\hline \multicolumn{3}{|l|}{ Age (Years) } \\
\hline$<40$ & Réf & 1 \\
\hline $40-49$ & $2.08(0.22-19.68)$ & 0.521 \\
\hline $50-59$ & $2.44(0.21-27.51)$ & 0.47 \\
\hline $60-69$ & $8.81(0.73-106.20)$ & 0.087 \\
\hline$\geq 70$ & $19.52(1.40-270.58)$ & $0.027^{*}$ \\
\hline \multicolumn{3}{|l|}{ Distant metastasis } \\
\hline M0 & Réf & 1 \\
\hline M1 & $2.37(0.67-14.07)$ & 0.097 \\
\hline \multicolumn{3}{|l|}{ Metastasis location } \\
\hline Absence & Réf & 1 \\
\hline Poumons & $0.78(0.30-2.01)$ & 0.609 \\
\hline Poumons, Os & $1.37(0.12-15.60)$ & 0.799 \\
\hline Vertèbre cervicale & $0.73(0.06-8.22)$ & 0.802 \\
\hline \multicolumn{3}{|l|}{ TNM tumour stage } \\
\hline Stage 1 & Réf & 1 \\
\hline Stage 2 & $2.04(0.66-6.27)$ & 0.212 \\
\hline Stage 3 & $1.22(0.38-3.91)$ & 0.731 \\
\hline Stage 4 & $3.32(0.71-15.55)$ & 0.127 \\
\hline \multicolumn{3}{|l|}{ Consultation delay (Months) } \\
\hline$<3$ & Réf & 1 \\
\hline$[3-6]$ & $2.97(0.57-15.26)$ & 0.192 \\
\hline$[6-12]$ & $3.16(0.50-19.71)$ & 0.216 \\
\hline$\geq 12$ & $2.24(0.48-10.33)$ & 0.298 \\
\hline \multicolumn{3}{|l|}{ Limits of surgical excision } \\
\hline Healthy & Réf & 1 \\
\hline Invaded & $1.11(0.49-2.48)$ & 0.792 \\
\hline \multicolumn{3}{|l|}{ Surgery } \\
\hline No sugery & Réf & 1 \\
\hline With chemotherapy & $0.42(0.11-0.68)$ & $0.039^{*}$ \\
\hline With radiotherapy & $0.45(0.35-0.77)$ & $0.019^{*}$ \\
\hline With chemotherapy + radiotherapy & $2.26(0.73-7.00)$ & 0.156 \\
\hline Exclusive & $5.41(0.98-29.92)$ & 0.053 \\
\hline
\end{tabular}




\section{Discussion}

In our study, the one-year, three-year, five-year, and eight-year overall survival rates are $70 \%, 18 \%, 3 \%$, and $1.5 \%$, respectively. Our overall one-year survival is similar to that found by Daneshi et al. in Iran for whom, the patients' 1-, 3-, 5-, and 10 -year survival rates were $81 \%, 62 \%, 53 \%$, and $38 \%$, respectively; in USA, the 5 -year relative survival rate was $46 \%$ for Supraglottis location, $76 \%$ for Glottis and 52\% for subglottis [14] [15]. But these results are lower than those of Zhang et al. in China with $99 \%$ and $100 \%$ respectively [16]. Our lower survival rate than that in the literature could be explained by the advanced stages consultation of our patients during the disease.

Our overall three-year survival is $18 \%$, it was higher than the overall survival rate in Brazzaville, which was estimated at 15\% [17]. But, our result is lower than those found by Balakrishna (45.7\%), Santos (61.4\%), Daneshi (62\%), even Zhang et al. in China in 2013 [with a rate of $81.5 \%$, [14] [16] [18] [19]. In another study, the 3-year survival rate for advanced stage was $61 \%$ [20]. This discrepancy between our series and the results of the literature could be explained by the non-compliance of patients, the non-compliance with medical monitoring for various reasons and the late diagnosis of the disease.

The overall five-year survival in our series is 3\%. Pezier et al. reported a $35.6 \%$ survival rate among American patients after 5 years of diagnosis, another study in the USA reported the 5-year survival rate of the patients as 53\%, [21] [22]. Daneshi reported about 53\% which is far below the data found in the literature [14]. The discrepancy between our series and the literature could be explained by the small size of our sample, the advanced stage during the diagnosis in our patients and the late diagnosis in the latter.

After analysis of the survival curves by the Log-Rank test, the factors that influenced survival in our study were: age, stage (TNM), presence of metastasis, surgical resection margin, type of treatment and consultation delay. These results agree with those of Boffeta et al. in Italy who found lymph node involvement, TNM stage, age, smoking and the location of the tumor [23]. Daneshi discovered significant relationship between patients' survival and age at diagnosis, disease stage, tumor grade, positive L. node, and type of treatment [14]. Brandstorp-Boesen et al. by studying Impact of stage, management and recurrence on survival rates in laryngeal cancer, revealed that, concerning the glottic cancer, surgical treatment improved overall survival, whereas old age, alcohol, T3-T4 status, positive $\mathrm{N}$-status and no treatment were associated with worse survival. In supraglottic, age, alcohol, and positive N-status had a significant impact on overall survival by multivariate analysis [24]. Zhang et al. also discovered that the surgical resection margin, clinical stage, and comorbidity were independent factors affecting the laryngeal cancer prognosis [16].

A study by Gourin et al. on patients with stage 4 of LC suggested that those with a higher $\mathrm{N}$ stage were at a greater risk of death. Accordingly, the risk of death in people at $\mathrm{N} 2$ and N3 stages was 2.29 and 2.96 times more than those at 
a N0 stage

The factors found above, influencing survival in our series, were re-analyzed according to the Cox model in order to estimate the Hazard Ratio. The resulting prognostic factors are: age: $\geq 70(\mathrm{HR}=19.52, \mathrm{p}=0.027)$ as a factor of poor prognosis; Surgical treatment associated with neoadjuvant chemotherapy (HR = $0.42, \mathrm{p}=0.039)$ and Surgical treatment associated with neo-adjuvant radiotherapy $(\mathrm{HR}=0.45, \mathrm{p}=0.019)$ as a factor of good prognosis. In most studies on the survival of patients with LC, age was considered as an important risk factor. Daneshi et al. illustrated that the risk of death in patients aged between 50 and 70 and patients over 70 was, respectively, 1.77 and 3.69 times more than those under 50 [14]. In a series of 1030 head and neck cancer patients, Lacy et al found that younger patients had a significantly better five year survival rate than middle aged or old patients [25]. Brandstorp-Boesen et al. in the study of supraglottic LSCC revealed that older age ( $>60$ years) was a significant negative prognostic factor [24]. Boffeta et al. in Italy concluded that patients in older age groups experienced significantly worse survival than younger patients, the difference being particularly relevant between patients aged $<70$ years at diagnosis and those aged $>70$ years at diagnosis [23]. Some others authors found no significant relationship between age and the risks of death [21] [26]. The advanced age would be a factor of poor prognosis could be justified first of all by the fact that the patients drag this pathology for a long time and thus arrive at advanced stages and should be noted that the more the patients age the lesser the support of side effects of different treatments

According to Bradford et al., Surgery and radiotherapy, either alone or in combination, are the conventional modalities for the management of squamous cell carcinoma of the larynx; in squamous cell carcinoma, chemotherapy in conjunction with radiotherapy is an alternative to laryngectomy in patients with advanced larynx cancer [9]. Wolf et al. found that good survival rates were achieved in patients selected for primary surgery, and both neoadjuvant chemotherapy and primary surgery had better survival rates than with concurrent chemoradiotherapy. Although the optimal individualized treatment approach for patients with advanced laryngeal cancer has not yet been defined, and likely does include surgery [27]. In the series of Iseh and Kufreh in 2011 in Nigeria, the combination of surgery and radiotherapy was a good prognostic factor as in our series [28]. The combination of surgery-radiotherapy, surgery-chemotherapy will have an advantage of limiting and controlling the evolution of the tumor, increasing the chances of completing remission and reducing recurrence and metastasis.

\section{Limitations of Study}

Our study concerned patients with laryngeal cancer in Cameroon, particularly in the cities of Yaoundé and Douala, and at the end of our recruitment we retained 80 patients out of the 101 files found between 10 years. During this study, we 
were stuck with problems such asthe absence and/or insufficiency of key information for our study: patient history, clinical examination data, anatomopathological, biological and morphological examination results. Notwithstanding these limiting parameters of our study, we nevertheless succeeded in identifying the prognostic factors and the survival of patients with laryngeal cancer in the Yaounde General Hospitals, Douala Gneral Hospital and Douala Laquintinie Hospital.

\section{Conclusion}

Present study showed that survival in laryngeal cancer in Cameroon is very low with a median overall survival of 1.41 years. The overall survival rates at 1 year, 3 years, 5 years and 8 years are $70 \%, 18 \%, 3 \%$ and $1.5 \%$, respectively. The age greater than or equal to 70 years is the poor prognosis factor, while receiving surgery in combination with neoadjuvant chemotherapy or surgery in combination with adjuvant radiotherapy is the factor of good prognosis.

\section{Conflicts of Interest}

The authors declare no conflicts of interest regarding the publication of this paper.

\section{References}

[1] Prades, J.M. and Reyt, E. (2013) Cancers du Larynx. EMC-Oto-Rhino-Laryngologie, 28, 1-15.

[2] Divi, V., Worden, F.P., Prince, M.E., Eisbruch, A., Lee, J.S., Bradford, C.R., et al. (2009) Chemotherapy Alone for Organ Preservation in Advanced Laryngeal Cancer. Head Neck, 32, 1040-1047. https://dx.doi.org/10.1002\%2Fhed.21285

[3] Pinilla, M. and Gonzalez, F.M. (2001) Cervical Lymph Mode Involvement in Laryngeal Carcinoma: A Retrospective Study of 430 Cases. Acta Otorrinolaringológica Española, 52, 213-218. https://doi.org/10.1016/S0001-6519(01)78200-3

[4] Bonfils, P. (1996) Pathologie ORL et Cervicofaciale. Éditions Ellipses, Paris.

[5] Becker, M. (2000) Neoplastic Invasion of Laryngeal Cartilage: Radiologic Diagnosis and Therapeutic Implications. European Journal of Radiology, 33, 216-229. https://doi.org/10.1016/S0720-048X(99)00144-8

[6] Ndahindwa, V., Ngendahayo, L. and Vyankandondera, J. (2012) Aspects Epidemiologiques et Anatomopathologiques des Cancers dans les Centres Hospitaliers Universitaires (chu) du Rwanda. Revue Médicale Rwandaise, 69, 40-49.

[7] Kostev, K., Jacob, L., Kalder, M., Sesterhenn, A. and Seidel, D. (2018) Association of Laryngeal Cancer with Vocal Cord Leukoplakia and Associated Risk Factors in 1,184 Patients Diagnosed in Otorhinolaryngology Practices in Germany. Molecular and Clinical Oncology, 8, 689-693.

http://www.spandidos-publications.com/10.3892/mco.2018.1592 https://doi.org/10.3892/mco.2018.1592

[8] Rewari, A., Lu, H., Parikh, R., Yang, Q., Shen, Z., Haffty, B.G. (2009) BCCIP as a Prognostic Marker for Radiotherapy of Laryngeal Cancer. Radiotherapy \& Oncology, 90, 183-188. https://doi.org/10.1016/j.radonc.2008.10.020 
[9] Bradford, C.R., Ferlito, A., Devaney, K.O., Mäkitie, A.A. and Rinaldo, A. (2020) Prognostic Factors in Laryngeal Squamous Cell Carcinoma. Laryngoscope Investigative Otolaryngology, 5, 74-81. https://doi.org/10.1002/lio2.353

[10] Mighri, K., Lahmar, I. and Driss, N., Ghorbel, A.M., Njim, L., Lahmar, I., et al. (2010) Cancers du Larynx Etude Retrospective à Propos de 90 cas. Journal Tunisien d ORL et de Chirurgie Cervico-Faciale, 5, 31-35.

[11] Horner, M.J., Ries, L.A.G., Krapcho, M., Neyman, N., Aminou, R., Howlader, N., et al. (2009) SEER Cancer Statistics Review, 1975-2006. National Cancer Institute, Bethesda. http://seer.cancer.gov/csr/1975 2006/

[12] Nachalon, Y., Cohen, O., Alkan, U., Shvero, J. and Popovtzer, A. (2017) Characteristics and Outcome of Laryngeal Squamous Cell Carcinoma in Young Adults. Oncology Letters, 13, 1393-1397. https://doi.org/10.3892/ol.2016.5528

[13] Bengono, G., Fouda, A., Moune, A., Mvouni, S. and Njock, R. (2008) Prise en Charge des Cancers du Larynx au Cameroun: Expérience d'un Service ORL en Afrique Noire. Carcinologie Pratique en Afrique, 7, 2-5.

[14] Daneshi, N., Fararouei, M., Mohammadianpanah, M., Zare-Bandamiri, M., Parvin, S. and Dianatinasab, M. (2018) Effects of Different Treatment Strategies and Tumor Stage on Survival of Patients with Advanced Laryngeal Carcinoma: A 15-Year Cohort Study. Journal of Cancer Epidemiology, 2018, Article ID: 9678097. https://doi.org/10.1155/2018/9678097

[15] Howlader, N., Noone, A.M., Krapcho, M., Miller, D., Brest, A., Yu, M., et al. (2019) SEER Cancer Statistics Review, 1975-2016. National Cancer Institute, Bethesda. https://seer.cancer.gov/csr/1975 2016/

[16] Zhang, S.-Y., Lu, Z.-M., Luo, X.-N., Chen, L.-S., Ge, P.-J., Song, X.-H., et al. (2013) Retrospective Analysis of Prognostic Factors in 205 Patients with Laryngeal Squamous Cell Carcinoma Who Underwent Surgical Treatment. PLoS ONE, 8, e60157. https://doi.org/10.1371/annotation/9c5dbeb2-9990-464e-a05d-72d329f11647

[17] Otouana Dzon, H.B., Diembi, S., Ngouoni, G.C., Bolenga Liboko, A. and Tsierie-Tsoba, A. (2020) Cancers of Larynx in Brazzaville: Management and Survival of Patients. Health Sciences and Disease, 21, 103-106.

[18] Yeole, B.B., Sankaranarayanan, R., Sunny, L., Swaminathan, R. and Parkin, D.M. (2000) Survival from Head and Neck Cancer in Mumbai (Bombay), India. Cancer, 89, 437-444. https://doi.org/10.1002/1097-0142(20000715)89:2<437::AID-CNCR32>3.0.CO;2-R

[19] Santos, T.S., Estêvão, R., Antunes, L., Certal, V., Silva, J.C. and Monteiro, E (2016) Clinical and Histopathological Prognostic Factors in Locoregional Advanced Laryngeal Cancer. The Journal of Laryngology \& Otology, 130, 948-953. https://doi.org/10.1017/S002221511600880X

[20] Yücel, B., Eren, A.A., Erdis, E., Babacan, N.A. and Altuntaş, E.E. (2013) Treatment Results, Side Effects and Prognostic Factors Affecting Survival in Patients with Larynx Cancer. Journal of Medical Updates, 3, 69-76.

https://doi.org/10.2399/jmu.2013002005

[21] Pezier, T.F., Nixon, I.J., Joshi, A., Guerrero-Urbano, T., Oakley, R., Jeannon, J.-P. and Simo, R. (2014) Factors Predictive of Outcome Following Primary Total Laryngectomy for Advanced Squamous Cell Carcinoma. European Archives of OtoRhino-Laryngology, 271, 2503-2509. https://doi.org/10.1007/s00405-013-2779-3

[22] Ganly, I., Patel, S.G. and Matsuo, J., Singh, B., Kraus, D.H., Boyle, J., et al. (2009) Predictors of Outcome for Advanced-Stage Supraglottic Laryngeal Cancer. Head \& 
Neck, 31, 1489-1495. https://doi.org/10.1002/hed.21113

[23] Boffetta, P., Merletti, F., Faggiano, F., Migliaretti, G., Ferro, G., Zanetti, R., et al. (1997) Prognostic Factors and Survival of Laryngeal Cancer Patients from Turin, Italy: A Population-Based Study. American Journal of Epidemiology, 145, 1100-1105. https://doi.org/10.1093/oxfordjournals.aje.a009072

[24] Brandstorp-Boesen, J., Falk, S.R., Boysen, M. and Brøndbo, K. (2017) Impact of Stage, Management and Recurrence on Survival Rates in Laryngeal Cancer. PLoS ONE, 12, e0179371. https://doi.org/10.1371/journal.pone.0179371

[25] Lacy, P.D., Piccirillo, J.F., Merritt, M.G. and Zequeira, M.R. (2000) Head and Neck Squamous Cell Carcinoma: Better to Be Young. Otolaryngology-Head and Neck Surgery, 122, 253-258. https://doi.org/10.1016/S0194-5998(00)70249-X

[26] Karlsson, T.R., Al-Azzawe, M., Aziz, L., Hurman, D. and Finizia, C. (2014) Survival Outcome Depending on Different Treatment Strategies in Advanced Stages III and IV Laryngeal Cancers: An Audit of Data from Two European Centres. European Archives of Oto-Rhino-Laryngology, 71, 547-554.

https://doi.org/10.1007/s00405-013-2657-z

[27] Wolf, G.T., Bellile, E., Eisbruch, A., Urba, S., Bradford, C.R., Peterson, L., et al. (2017) Survival Rates Using Individualized Bioselection Treatment Methods in Patients with Advanced Laryngeal Cancer. JAMA Otolaryngology_Head \& Neck Surgery, 143, 355-366.

[28] Iseh, K. (2011) Total Laryngectomy for Laryngeal Cancer in a Nigerian Tertiary Health Center: Prognosis and Outcome. Journal of Surgical Technique and Case Report, 3, 23. http://dx.doi.org/10.4103/2006-8808.78467 